\title{
A-3 COMPARTIENDO LA OTREDAD. LOS www.aibr.org \\ ENCUENTROS CON LA HISTORIA EN LA TEORÍA ANTROPOLÓGICA CONTEMPORÁNEA
}

\section{Elisa Cragnolino}

Profesora adjunta e Investigadora de la Facultad de Filosofía y Humanidades y del Centro de Estudios Avanzados de la Universidad Nacional de Córdoba, Argentina. Dirección: Pabellón Agustín Tosco. $1^{0}$ Piso Ciudad Universitaria. Córdoba (5000) Argentina. E-mail: elisacragnolino@ciudad.com.ar. Tlfno.54-0351-4719274

\begin{abstract}
Resumen
Nos proponemos en este trabajo analizar la presencia de la dimensión histórica en la teoría antropológica contemporánea. Dado lo vasto y complejo de dicho proceso y los límites del presente artículo realizaremos un rápido recorrido que se detendrá particularmente en algunos de los momentos de esta confluencia: la primera mitad del siglo; los desarrollos de la posguerra y en particular las propuestas del dinamismo, el estructuralismo y los enfoques marxistas. Haremos luego una breve mención al desarrollo historiográfico más reciente y a aquellas perspectivas en que la influencia de la antropología aparece más claramente, la denominada "historia antropológica".
\end{abstract}

\section{Palabras clave}

Teoría antropológica; siglo XX, historia

\begin{abstract}
We herein propose the analysis of the historical dimension within the contemporary anthropological theory. Given the vastness and the complexity of that process, we will run through the words up to some particular times: the fist half of the XX century; the post world war II; and specially the propositions of Dynamism, Structuralism and the Marxist approach. Then we will briefly point out the recent developments in historiography an those perspectives more clearly influenced by anthropology.
\end{abstract}

Key words

Anthropological Theory ; XX century; history

\section{Introducción}

$\mathrm{H}^{\circ}$ oy abundan las referencias hechas "casi maquinalmente", diría Auge (1995) a la "dimensión antropológica" del objeto o método en trabajos de historia pero también de sociología, educación, geografía. Hay una corriente dentro de la 
historiografía contemporánea, desarrollada especialmente desde los 80 , que incluso se denomina "historia antropológica" o "historia etnográfica". A su vez hoy están vigentes enfoques antropológicos que, reconociéndose en su abordaje propio y en su metodología, se afirman historicistas.

Pero los encuentros e intercambios entre antropología e historia no son nuevos; son elementos constitutivos de la historia de estas dos disciplinas y han estado presentes, en el caso de la antropología desde sus orígenes.

Lo que nos proponemos en este trabajo es precisamente analizar la presencia de la dimensión histórica en la teoría antropológica contemporánea. Dado lo vasto y complejo de dicho proceso y los límites del presente artículo realizaremos un rápido recorrido que se detendrá particularmente en algunos de los momentos de esta confluencia. Haremos, a su vez, una breve mención al desarrollo historiográfico más reciente y a aquellas perspectivas en la que la influencia de la antropología aparece más claramente.

\section{La antropología de la primera mitad del siglo XX}

El nacimiento de la antropología vinculado con el período colonial y la construcción tradicional del objeto antropológico: el estudio del presente de las sociedades "primitivas", "la gente sin historia", han facilitado las acusaciones de "antihistoricismo" hechas a la antropología en su conjunto.

Pero si tomamos la historia de esta disciplina la problemática de la temporalidad está presente desde el evolucionismo, su esquema histórico universal y la reacción boasiana abordando los procesos de diversificación de la humanidad. Este "diálogo" entre "dos pilares de la antropología " (Tylor y Boas) son en realidad, dice Auge (1995:12) "[...] diálogos entre dos concepciones de la historia o de las relaciones entre antropología e historia, entendida la primera como el estudio de las culturas (que son conjuntos funcionales de "rasgos" culturales) y entendida la segunda como el estudio de la circulación de esos "rasgos" (su difusión) y/o entendida como identificación de una situación en una escala de la evolución".

Desde el funcionalismo de Malinowski y el estructural funcionalismo de Radcliffe-Brown se critica al evolucionismo y difusionismo por que, a pesar de sus diferencias, convergen en sus limitaciones en relación con el análisis histórico: su 
historia no pasaba de ser conjetural e ideológica. Los estadios del evolucionismo y los ciclos o los complejos culturales del difusionismo son calificados, en este sentido, como el fruto de una abstracción que carece de testimonios corroborativos. ${ }^{1}$

Según el fundador del estructural funcionalismo británico, Radcliffe-Brown, "los métodos diferentes" para explicar los hechos culturales, el histórico y el inductivo debían mantenerse cuidadosamente separados, reservando a la antropología social el estudio "[...] puramente inductivo de los fenómenos culturales, que aspire a descubrir leyes generales" (Radcliffe-Brown, 1985: 46)

Establecida como disciplina científica, con el auge del funcionalismo, y habiéndose redefinido la utilidad del conocimiento antropológico para ser aplicado en la administración colonial, la antropología debía desprenderse de las pretensiones de reconstruir el pasado histórico de la humanidad. Son significativas en este sentido las palabras de Radcliffe-Brown cuando señala que los intentos de reconstruir la historia de las culturas y de los pueblos, a los que denomina etnología, "[...] no son del más mínimo valor práctico para las tareas de la administración o de la educación de los indígenas" (Radcliffe-Brown, 1985: 48). El estudio de las creencias y costumbres de los pueblos indígenas debía realizarse con el objetivo, no de reconstruir su historia, sino descubrir su significado, su función, etc., porque " [...] ese conocimiento era de gran ayuda para el misionero o el funcionario encargado de hacer frente a los problemas prácticos de la adaptación de la civilización indígena a las nuevas condiciones resultantes de la ocupación del país". (1985:53)

Dentro del funcionalismo británico se destaca, sin embargo, como una voz discordante, Evans-Pritchard quien fue uno de los primeros que bregó por la visualización de la antropología como ciencia histórica. Si bien considera que la sociedad es un sistema, niega que esté sujeta a leyes naturales y propone que el conocimiento del pasado facilita una comprensión más profunda de la vida social.

En una conferencia desarrollada en $1961^{2}$, explícita claramente su posición acerca de la importancia de la dimensión histórica y señala las consecuencias negativas y empobrecedoras del análisis que para la antropología social tuvo su ruptura con la historia:

\footnotetext{
1 "Las hipótesis no verificadas y generalmente imposibles de verificar sobre los orígenes no son de la más mínima utilidad para nuestra investigación de leyes demostrables" (Radcliffe Brown, 1975:44).

${ }^{2}$ Publicada como " antropología e historia" en Ensayos de antropología Social (1974)
} 
- Los antropólogos, dice Evans-Pritchard (1974), raramente han hecho serios esfuerzos para reconstruir con documentos históricos y tradición oral del pasado del pueblo que estudiaban y cuando han recurrido a fuentes documentales han sido escasamente críticos con las mismas.

- Debido a la falta de estas reconstrucciones se plantean conjeturas, la mayoría de las veces falsas, acerca del carácter estático de los pueblos primitivos.

- Al renunciar a la historia han privado a la antropología de la comprensión de la complejidad de los fenómenos e instituciones, ya que la historia tradicional de estos pueblos es parte de la vida social actual que observa el antropólogo y también porque un conocimiento inteligente de los mismos implica saber no solamente lo que son sino también cómo llegaron a serlo ( $y$ en esto coincide con Boas). No aprovechan tampoco el conocimiento construido por historiadores o sociólogos historiadores que pueden proveer a la antropología de términos y conceptos.

- La tendencia a sobrestimar estudios etnográficos funcionales a expensas de los estudios sobre desarrollo y a ignorar los hechos históricos han impedido verificar la validez de las proposiciones del estructural-funcionalismo en contextos de cambios.

- Por último, así como la historiografía constituye un campo importante del estudio sociológico y se configura como parte de la sociología del conocimiento, también es necesario el desarrollo de una sociología de la antropología social que recupere este conocimiento histórico de la disciplina y contextualice este pensamiento social en un presente en continua transformación. (Evans-Pritchard, 1974).

En Estados Unidos el "Gran Boas" también cuestionaba a los británicos, pero desde un lugar diferente, la concepción unilineal del evolucionismo tayloriano. Desde su enfoque, el particularismo histórico, que domina el panorama antropológico norteamericano durante la primera mitad del siglo, postula la necesidad de construir un enfoque histórico de la cultura. La idea de que la cultura es un sistema cerrado, que es único e irrepetible al igual que un acontecimiento histórico, estaba de acuerdo con la tradición de los historicistas alemanes que traía Boas de su formación inicial en Europa. 
Boas propone que el conocimiento de los hechos sociales surge de una inducción hecha a partir del conocimiento individual y concreto de grupos localizados en el espacio y en el tiempo. Esta a su vez sólo puede resultar de la historia de cada grupo. Pero el objeto de los estudios etnográficos es tal que esta historia permanece, en la mayoría de los casos, fuera del alcance del antropólogo.

Como dirá más tarde Lévi-Strauss (1984:9) "Para hacer la historia de sociedades sobre las cuales poseemos datos que desalentarían al historiador, Boas aplica las exigencias del físico, pero de hecho sus rigurosas investigaciones sólo alcanzan 'la historia del instante fugitivo', 'una microhistoria' que se relaciona tan poco con el pasado como la 'macrohistoria' del evolucionismo o el difusionismo".

A esta pueden sumarse otras críticas:

- El relativismo cultural, una de las principales tesis derivadas de este enfoque y que significó un avance importante en relación con las posiciones etnocéntricas del evolucionismo, supone culturas aisladas, que pueden entenderse en sí mismas y oculta, como señala García Canclini (1984), las relaciones de interdependencia mundial y los procesos de subordinación que implica el capitalismo.

- Al afirmarse en el inductivismo y el relativismo, el particularismo se convierte, pese a sus postulados en contrario, también en ahistórico al volverse a teórico. Esto es porque al querer evitar las generalizaciones características del evolucionismo (las grandes teorías) cae en un empirismo extremo. No tiene en cuenta que la recolección sistemática de datos sobre una cultura presupone ya toda una serie de conceptualizaciones y decisiones de carácter teórico que son también un producto histórico.

\section{La antropología de posguerra}

La vigencia de las ideas de Boas y sus discípulos de la escuela de antropología Cultural acerca de la cultura como todo integrado y armónico y las de la sociedad como sistema en equilibrio del estructural funcionalismo se quiebra después de la Segunda Guerra Mundial.

La crisis de la dominación colonial, las rebeliones nacionales de la década del 60 en África y Asia y los consiguientes movimientos sociales conducen a un 
cuestionamiento de las interpretaciones antropológicas institucionalizadas que, en tanto suponen una visión estable, armónica, integrada de la sociedad, se oponen a la realidad que se evidenciaba en estos procesos.

En estas nuevas construcciones de la teoría antropológica se redescubre la historia. Veamos entonces algunos de estos replanteamientos.

\section{El dinamismo de Gluckman y Balandier}

Frente al ahistoricismo de la mayor parte de los análisis funcionalistas el dinamismo recuperará todos aquellos procesos que antes eran concebidos como "disfuncionales" y sostendrá que, si bien las sociedades se encuentran en alguna forma de equilibrio, este es dinámico e incluye cambio y conflicto. Es decir centra su atención preferentemente en los procesos, en los aspectos diacrónicos, de lo cual resulta un resurgimiento de los estudios históricos.

Gluckman (1963), criticando la "visión simplista" de Malinowski acerca del cambio cultural en Africa ${ }^{3}$, subrayará la importancia del conflicto en la vida social y la consideración de los diferentes componentes de las sociedades africanas colonizadas como parte de un mismo "campo social".

En su trabajo "Order and Rebellion in Tribal Africa" propone que cada sistema social es un campo de tensiones, de cooperación pero también de luchas. Analizando la sociedad zulú, plantea que el conflicto en lugar de destruir la cohesión social la hace posible al producir una renovación de las estructuras sociales. De este modo la rebelión aparece entre estos pueblos como un elemento esencial en el proceso de las sucesiones políticas pues, lejos de poner en peligro el régimen de la realeza, tiende a reforzarla.

Esta teoría, al postular el estudio del dinamismo en la continuidad estructural y el rol integrador de los conflictos, somete el concepto de estructura a la prueba de la historia; hace progresar los métodos y técnicas de análisis al recurrir a la diacronía.

\footnotetext{
${ }^{3}$ Intentando construir un modelo de cambio para el análisis de la sociedad africana, Malinowsky propone examinar separadamente tres conjuntos culturales: la cultura tradicional, la cultura occidental y la surgida de la puesta en relación de las dos primeras. Postula que la relación entre africanos y europeos debía equilibrarse a trav,s de la creación de medidas comunes para ambas culturas. Su visión del proceso de cambio producido a partir del contacto no conflictivo entre culturas iguales, fue
} 
Según Gluckman el método dinámico no rechaza el estructuralismo; pero el investigador una vez hecha la investigación sincrónica debe también buscar material histórico. Analizar entonces estas observaciones según las variaciones en el tiempo para poder establecer la duración estructural de cada institución y los cambios observados.

El enfoque dinamista en relación a la "situación colonial" fue desarrollado también en la Francia de postguerra por George Balandier quien publica en 1955 su "Sociologie Actuelle de 'I Afrique Noire". El cambio social es visto por este autor desde la perspectiva de la dominación.

Observa Balandier que los estudios antropológicos de los pueblos africanos se habían llevado a cabo, hasta ese momento, por referencias a la economía y la organización social primitivas en función de los trastornos causados por la economía "moderna", pero que la economía colonial no había sido incluida en sus contextos analíticos. Estaba ausente el "campo de las relaciones complejas que constituyen la realidad social y las relaciones antagónicas que se plasman en ella" (Balandier, 1963: 10). Adolecían de la referencia a la sociedad global que es la colonia o lo que da en llamar "la situación colonial" que debe ser considerada en su conjunto y en tanto que sistema. (Balandier, 1963:24). ${ }^{4}$

J. Copans sugiere que los principios básicos de este marco teórico pueden resumirse de la siguiente manera: (Llobera, 1980: 189)

"1) Las sociedades africanas tienen una historia (tradicional y moderna): son dinámicas y contradictorias. 2) Los movimientos sociales e ideológicos actuales reflejan la estructura del pasado y las transformaciones provocadas por la situación colonial. 3) La situación colonial es un fenómeno global que puede caracterizarse por su naturaleza no igualitaria".

duramente criticado por aquellos antropólogos preocupados por los procesos de conflicto, ya que oculta los verdaderos móviles de la expansión capitalista. (Harris, 1985).

${ }^{4}$ Las características más salientes de esta situación son: "el dominio impuesto por una minoría extranjera, racial y culturalmente distinta, en nombre de una superioridad social (o étnica) y cultural dogmáticamente afirmada, sobre una mayoría autóctona materialmente inferior; el contacto establecido entre civilizaciones heterogéneas: una civilización basada en el maquinismo, en una economía potente de un ritmo r pido y de origen cristiano, se impone a unas civilizaciones sin técnicas complejas de economía atrasada..; el carácter antagónico de las relaciones establecidas entre ambas sociedades, carácter que se explica por el papel instrumental al que está condenada la sociedad colonizada; la necesidad de recurrir no solo a la fuerza sino también a un conjunto de pseudojustificaciones y de comportamientos estereotipados para mantener la dominación..." (Balandier, 1963: p. 34-35). 
Copans señala además que la aparición de la sociología de Balandier ha implicado una triple ruptura con la antropología tradicional francesa: " [...] empírica (de lo sincrónico a lo diacrónico), metodológica (del nivel local al nacional) y teórica (del idealismo al materialismo)" (Llobera, 1980: 189).

El funcionalismo dinámico de Balandier comparte el escenario de la antropología francesa de posguerra con el estructuralismo. Ambos, a su vez, constituyen el horizonte inmediato de los antropólogos marxistas franceses (Meillasoux, Godelier, Terray, Rey) de los que nos ocuparemos más adelante. Detengámonos ahora en Lévi-Strauss.

\section{El estructuralismo: ¿la negación de la historia?}

La "profesión de fe histórica" expresada por Lévi-Strauss en su Clase Inaugural en el Colegio de Francia en 1960, parece haber convencido a pocos. En efecto, una de las principales críticas efectuadas al estructuralismo, desde diferentes orientaciones, es su ahistoricidad.

Para Lévi-Strauss la estructura tiene primacía sobre la historia y el tiempo histórico no es sino la posibilidad de que se manifiesten las invariantes estructurales. Este planteamiento implica una determinada relación entre antropología/etnología e historia: Ambas, dirá Lévi-Strauss, estudian otras " [...] sociedades que no son esta en que vivimos (alteridad que resulta de la distancia en el tiempo o en el espacio o también de una heterogeneidad cultural" (Lévi-Strauss, 1984: 17)

La diferencia fundamental entre etnología e historia no es de objeto (es la vida social), ni de propósito ("una mejor inteligencia del hombre"), ni de método (que solo varía en cuanto a la dosificación de los procedimientos de la investigación). Se distinguen por la elección de perspectivas complementarias: La historia organiza sus datos en relación con las experiencias conscientes de la vida social. La etnología en relación con las condiciones inconscientes. ${ }^{5}$

\footnotetext{
5 "[...] si la actividad inconsciente del espíritu consiste en imponer formas a un contenido, y si estas formas son fundamentalmente las mismas para todos los espíritus, antiguos y modernos, primitivos y civilizados - como lo muestra el estudio de la función simbólica, tal como se expresa en el lenguaje-, es necesario y suficiente alcanzar la estructura inconsciente que subyace en cada institución o costumbre para obtener un principio de interpretación válida para otras instituciones y otras costumbres, a condición, naturalmente, de llevar lo bastante adelante el análisis". (Levi-Strauss, 1984: 21).
} 
El método etnológico y el método histórico convergen para llegar a esta estructura inconsciente. No sólo el análisis de las estructuras diacrónicas sino también las sincrónicas, implican un constante recurrir a la historia. Sólo esta permite extraer, al poner de manifiesto instituciones que se transforman, la estructura subyacente a formulaciones múltiples y permanente a través de una sucesión de acontecimientos.

La etnología, en consecuencia, no puede permanecer indiferente a los procesos históricos ni a las expresiones conscientes de los fenómenos sociales. Pero concediéndole la misma atención que el historiador, le interesa eliminar todo lo que ellos deben al acontecimiento y la reflexión; busca "a través de un consciente que jamás ignora, un sector cada vez mayor del inconsciente hacia el cual se dirige" (Lévi-Strauss, 1984: 25).

Más allá de la imagen consciente que los hombres tienen de su historia, la etnología trata de alcanzar el "inventario de posibilidades inconscientes" (cuyo número no es limitado) el "repertorio de esas posibilidades", la "arquitectura lógica" de desarrollos históricos que pueden ser imprevisibles, pero nunca arbitrarios ( LéviStrauss, 1984: 24).

Pero así planteada la relación entre antropología e historia, lo que LeviStrauss propone, más que "perspectivas complementarias" (como lo postula en antropología estructural), es una jerarquización en la que la segunda se convierte en una ciencia auxiliar de la primera.

La historia es un instrumento para proveer materiales, indicar invariantes, ayudar al señalamiento de tipos; pero solo adquiere sentido y es inteligible si se la confronta "con el repertorio de las posibilidades" (Gaboriau, 1969). ${ }^{6}$

¿Es posible entonces aprender el movimiento histórico, la diacronía de lo social, en un análisis que conserve el rigor estructural?

La respuesta, al menos como declaración de principio, es afirmativa. Tanto en el totemismo en la actualidad como en la lección inaugural señala que el análisis estructural puede aplicarse en el estudio del devenir y niega la antinomia sincronía diacronía. Acepta incluso el determinismo histórico. "[...] la dialéctica estructural no

\footnotetext{
${ }^{6}$ Vease por ejemplo el capítulo IV de El pensamiento salvaje "Totem y casta" en el que Lévi-Strauss estudia los estados intermedios entre una sociedad totémica y una de castas, estableciendo un cuadro de las variantes reales o posibles, actualizadas por sociedades diferentes.
} 
contradice al determinismo histórico: solicita su concurso y le proporciona un nuevo instrumento" (Levi-Strauss, 1984: 218).

Sin embargo, como lo señala Gaboriau (1969) la historia estructural es más un proyecto que una realidad; sólo encuentra en las obras de Lévi-Strauss direcciones de investigación para el estudio diacrónico: la búsqueda de factores internos de desequilibrio, influencias del exterior que introducen cambios, inadecuación y torsiones entre los sistemas; pero no ha explicitado los pasos a seguir para descubrir las estructuras y los cambios.

Lo que sí aparece, en cambio, es su negación a " [...] la historia que quiere explicar el sentido del tiempo vivido por los hombres": lo considera un mito más que el método estructural puede estudiar como cualquier otro mito. Remite como ejemplo a la "Crítica de la razón dialéctica" (Levi-Strauss,1975: 368). Se opone duramente a los filósofos de la historia para quienes la diacronía y el devenir temporal gozan de un privilegio especial, como si fundasen un tipo de inteligibilidad superior que la sincronía, a través de la cual pudieran alcanzar el ser mismo del cambio.

Sobre estas cuestiones, estructura e historia, razón analítica y razón dialéctica, gira su polémica con Sartre, la que en definitiva se transforma para LeviStrauss "en una requisitoria contra el historiador y la historia" (Lefebvre, 1969:145). Mientras que para Sartre hay un primado de la historia que parece absorber la especificidad de las estructuras, para Levi-Strauss hay un primado de la estructura que no explica la especificidad de la historia.

Para este último, en síntesis, la búsqueda de la inteligibilidad no culmina con la historia, al contrario es un punto de partida, pero que sirve solo a condición de "salir de ella", remontarse hasta los invariantes de la estructura. Es necesario y suficiente alcanzar la estructura inconsciente que subyace en cada institución y costumbre para obtener los principios de interpretación válidos.

Aunque Lévi-Strauss proclame haber sido influenciado por Marx, no puede, ciertamente, reivindicarse marxista, materialista histórico. Al transformar a la antropología en una metafísica de las estructuras, su posición parece en cambio emparentada con el idealismo que Marx combatía.

En ocasiones Lévi-Strauss acepta la importancia de la infraestructura, "reafirma la autonomía de la superestructura hasta el punto de que la unidad orgánica de la 
sociedad queda minimizada e incluso eliminada completamente" (Llobera, 1980: 189)

El discurso lévistrossiano en relación con la historia ha sido también cuestionado y calificado, cuanto menos, de "ingenuo" cuando trata de dividirla en "fría" y "caliente". La primera es característica de la sociedad primitiva, que trata de perpetuarse como un reloj; producen muy poco desorden y tienen una tendencia a mantenerse indefinidamente en su estado inicial; manifiestan una entropía baja, funcionando en una especie de "cero absoluto" de temperatura histórica. La segunda, en cambio, es asignada a las sociedades del mundo occidental las que, al igual que las máquinas de vapor, utilizan para su funcionamiento una diferencia de potencial (relacionado con sus diferencias internas, su desequilibrio) que le permite extraer de ella "futuro" y "energía".

Pero, si en definitiva bajo esta apariencia de movimiento que caracteriza a la sociedad moderna, Lévi-Strauss ve la estabilidad eterna de estructuras permanentes y asigna a la antropología la tarea de descubrir estas metaestructuras fundadoras de la vida social, ¿no está renunciando de antemano a la historia?

En esta renuncia a la historia coinciden justamente las críticas a la propuesta lévistrossiana, que es calificada como "conservadora".

\footnotetext{
"Esta abdicación de la antropología transformada en metafísica de las estructuras - que en Lévi-Strauss ha llegado a la explícita negación de la iniciativa humana como iniciativa de libertad y a la aceptación de un determinismo nos evita el riesgo de asumir un compromiso personal auténtico [...] Contradice la vocación de una antropología cultural críticamente comprometida con la acción y la transformación [...] La evasión metafísica fue siempre una de las más eficaces armas de la conservación" (Tullio-Altan, 1969:106-108)
}

Josep Llobera sostiene al respecto que, aunque Lévi-Strauss negaría que el estructuralismo tuviera implicaciones políticas, este favoreció cierto tipo de estudios (objetos formales o sociedades primitivas del presente etnográfico) y con ello dejó de explicar sociedades contemporáneas en un estadio determinado del desarrollo del capitalismo. "Es en este sentido que representó la ideología escapista por excelencia de la burguesía" (Llobera, 1980: 188) 
Los años 70. El marxismo estructuralista y la escuela de la economía política

En la década del 60 comienza a desarrollarse en ciertos ámbitos de la intelectualidad europea, sobre todo francesa, lo que Llobera (1980) Ilama un "marxismo creador y antidogmático" que implicar una profunda revisión de la concepción de la historia que la academia soviética, sobre todo a partir de Stalin, había legitimado.

Esta historia "oficial", tal como aparece en la obra de Stalin "Materialismo histórico y materialismo dialéctico", está reducida al desarrollo de fuerzas productivas (en el esquema vertido en términos de tecnología) y relaciones de producción. Se trata de una historia sucesiva de cinco etapas unilineales, correspondientes a los modos de producción, en las que dogmáticamente se ponía al "socialismo real" como el máximo escalón evolutivo de la sociedad humana.

Althusser y Balibar (1978) proponen, a partir de una "lectura sintomática" de los textos fundamentales de Marx y Engels, la construcción de la ciencia del materialismo histórico. El punto de partida es considerar que Marx abrió a la ciencia el continente de la historia y esto representa una ruptura epistemológica con respecto a la ideología anterior.

La novedad de esta concepción de la historia se encuentra en su propuesta de un nuevo criterio de periodización: la sucesión de totalidades sociales, modos de producción. Althusser señala que esta sucesión no es lineal, no se produce en el tiempo "histórico", sino que tiene un tiempo propio y leyes propias. Aunque existan conceptos generales del materialismo histórico cada modo de producción exige, en consecuencia, conceptos específicos.

Las categorías "modos de producción" (objeto teórico abstracto) y "formación social" (objeto real y concreto) son dos de los conceptos que permitirían construir con rigor teórico los procesos de formación y transformación de los modos de producción que se dieron en la historia.

El método propuesto por Althusser consiste en reconstruir los distintos modos de producción por medio de la combinación variada de los elementos invariantes de la instancia económica (trabajador, medios de producción, no trabajador) según las 
relaciones de propiedad y de apropiación real que pertenecen a la estructura de todo modo de producción.

En teoría esta operación podría producir un cuadro de todos los modos de producción "posibles". Y los plantea como posibles porque muchos de estos modos no han llegado nunca a "realizarse" ni han sido dominantes en formación social alguna. " [...] nunca han existido en forma independiente [...] no pertenecen a la periodización". (Althusser y Balibar, 1978: 236)

Aunque se destaca el aporte realizado por Altusser y Balibar al incorporar al análisis de totalidad social los niveles político e ideológico, que resultan claves para el análisis de la reproducción social ${ }^{7}$, las críticas hacia la perspectiva althusseriana tienen que ver esta propuesta de abstracción teórica y construcción de modelos formales. Modelos que esconden una concepción de la historia al que autores como Hindess y Hirst (1979) no dudan en calificar de "teleológica e idealista"

Coincidiendo con esta crítica, E. P. Thompson señala que "el estructuralismo estático" de Althusser", con su énfasis sobre la autonomía relativa y la determinación en última instancia tergiversa o elude los problemas centrales del materialismo histórico y cultural. "[...] como la hora fatal de la última instancia nunca suena, podemos al mismo tiempo, mostrar una piadosa reverencia frente a la teoría y hacer luego de nuestra capa un sayo en nuestra práctica" (Thompson, 1992: 80)

Este historiador inglés, sobre el que ya volveremos, en su trabajo The Poverty of Theory and Other Essays (1978) señala que la epistemología althusseriana se encuadra dentro de los planteos del idealismo: Por un lado al mostrar una indiferencia total hacia la realidad empírica y generar sobre si mismo un universo conceptual que es contrario al método histórico de Marx (las estructuras sólo pueden reconocerse teóricamente; por tanto la investigación empírica es incapaz de desvelarlas). Por otro, al afirmar que la historia es un proceso sin sujeto, convirtiendo a este simplemente en "soporte" de las relaciones de producción. (Para Althusser los verdaderos "sujetos", en el sentido de sujetos constituyentes de proceso, no son

\footnotetext{
${ }^{7}$ Tomando distancia del determinismo económico, Althussser y Balibar (1978) conciben el modo de producción como una combinación específica de diversas estructuras que se representa en tres niveles o instancias autónomos e interrelacionadas: la económica (infraestructura), la político jurídica y la ideológica (superestructura). En esta combinación de estructuras, si bien poseen una "autonomía relativa" están relacionados de tal manera que el económico es siempre el "determinante en última instancia", ya que determina cuál es la dominante en el modo de producción.
} 
los agentes sino las relaciones de producción [y las relaciones sociales, políticas e ideológicas])

Estos posicionamientos frente a la historia y el marxismo, ya sea negando o aceptando el liderazgo de Althusser, fueron retomados en el campo mismo de la antropología social.

Según Ortner (1984: 139) el marxismo estructuralista fue la única escuela desarrollada enteramente dentro de este campo y probablemente por esta razón fue la primera en producir un impacto sobre ella. "[...] se constituyó en un intento de revolución intelectual, y si bien no logró consolidarse como la única alternativa a todo lo preexistente, ciertamente fue exitosa en conmover gran parte del saber recibido" Veamos rápidamente a quienes Llobera (1980) identifica como representantes de la primera y segunda generación de antropólogos marxistas franceses y sus proposiciones acerca de la historia.

Godelier trabajó con Lévi-Strauss y esto marca uno de los desacuerdos teóricos centrales con respecto a Meillasoux; ya que mientras para el primero el estructuralismo de Lévi-Strauss representa un progreso científico, para el segundo, que tiene la influencia de Balandier, no es más que una ideología mistificante.

Godelier en "Sistema, estructura y contradicción en El Capital", (publicado en 1966) encuentra en Marx las raíces del estructuralismo y el puente que une "El Capital" con "Las estructuras elementales del parentesco de Lévi-Strauss".

Para Marx el conocimiento científico del sistema capitalista consiste en descubrir, más allá de su funcionamiento visible, su estructura interna oculta. Por lo tanto para él como para Lévi-Strauss "las estructuras no se confunden con las relaciones sociales visibles, sino que constituyen un nivel de la realidad invisible. La lógica de estas, y más generalmente las leyes de la práctica social, dependen del funcionamiento de esas estructuras ocultas, cuyo descubrimiento debería permitir informar sobre todos los hechos observados". (Godelier, 1967:52)

Para ambos además el estudio de la estructura es un prerrequisito del estudio de la historia. "El estudio del funcionamiento interno de una estructura debe preceder y aclarar el estudio de su génesis y evolución" (Godelier, 1967:61). El punto de partida obligado es pues el descubrimiento y definición del elemento invariable y relaciones para dar paso luego al estudio de las variaciones compatibles con la reproducción del mismo. $Y$ aquí se da el paso a la historia. Resultan posibles 
estudios sincrónicos y diacrónicos; análisis de los diversos estados de una estructura que corresponden a diferentes momentos de su evolución.

Pero ¿cómo se explica la génesis de nuevas estructuras? Aquí Godelier intenta superar las limitaciones del estructuralismo apelando al concepto de contradicción. Este concepto, sin embargo, no debe interpretarse en sentido hegeliano con la hipótesis de "identidad de los contrarios". ${ }^{8}$ La noción de contradicción de Marx supone que las contradicciones que surgen del funcionamiento de una estructuran expresan los límites objetivos de su posibilidad de reproducirse, de quedar en lo esencial invariables y tienen en parte su condición de aparición y de resolución en el exterior de esta estructura. Si además "[...] ninguna estructura es reductible a otra, ninguna finalidad interna regula la evolución de la naturaleza y de la historia". (Godelier, 1967: 86) Sobre esta base, dirá Godelier "debería ser posible establecer un nuevo diálogo entre estructuralismo y marxismo" y apelando a una diacronía estructural superar la oposición entre estructura y acontecimiento, entre antropología e historia.

Sin embargo, según LLobera, la ciencia de la historia que propugnaba Godelier en los años 60 quedó "como un paso importante aunque insuficiente" y sus estudios prácticos emprendidos desde entonces han ignorado "la historia real". Esta última "[...] consiste en pasar de una morfología estructuralista a una fisiología estructural, es decir a una teoría de las condiciones y razones que explican el cambio de locus de las relaciones de producción [...] (Godelier) parece ser un marxista que ha evitado una de las cuestiones más centrales en Marx: el presente como historia" (Llobera, 1980:225)

Terray (discípulo de Althusser y perteneciente a lo que Llobera llama la segunda generación de antropólogos marxistas franceses), considera, al igual que Godelier, que las "sociedades primitivas" son una esfera apropiada donde confirmar la validez universal del materialismo histórico.

En su trabajo "El marxismo ante las sociedades primitivas" (1971) propone anexar el terreno de la antropología social al ámbito del materialismo histórico, para demostrar la validez universal de los conceptos y de los métodos elaborados por Marx. Consagrada a las formaciones económicas sociales en las que "el modo de

\footnotetext{
${ }^{8}$ El idealismo hegeliano, fundado en "la identidad de los contrarios" que intenta demostrar que existe una solución interna en la contradicción interna de una estructura, "es exactamente opuesta a la de Marx y hace la dialéctica inutilizable para la ciencia" (Godelier, 1967: 81).
} 
producción capitalista está ausente", esta "sección particular" del materialismo histórico requeriría la colaboración de historiadores y etnólogos.

Esta propuesta alentaba el paso de los estudios históricos abstractos a los concretos, dando cuenta en el tiempo de las formas sucesivas de organización de las relaciones de producción y sus transformaciones. (Terray personalmente lo intentar estudiando la historia del reino Abron de Gayman, en el Africa Occidental).

Pero la propuesta de Terray ha sido criticada desde diferentes lugares, incluso desde el mismo campo de la antropología marxista francesa (por ejemplo por Meillasoux y Rey). Se le cuestiona:

- La validez de la traslación de los conceptos del marxismo, surgidos para dar cuenta de la lógica de la sociedad capitalista, en el análisis de la historia de "sociedades primitivas" y los problemas metodológicos derivados del mismo. ${ }^{9}$

- La idea de constituir a la antropología en una "disciplina regional" del materialismo histórico que estudiaría aquellas sociedades en las que el modo de producción capitalista no se encuentra o si aparece lo hace en tanto hecho externo.

Se asume de esta manera, dicen sus críticos, una formulación clásica del objeto antropológico que pretende descubrir "estadios originarios", y que desconoce que estos objetos aislados, estas sociedades como entidades más o menos cerradas, pertenecen a estructuras más amplias cuya historia debe ser descifrada. Las sociedades estudiadas por los antropólogos son resultado de una compleja historia de vinculaciones (expresadas en términos de "articulación" o "subsunción") del capitalismo y "otras formaciones económico-sociales" y la antropología social actual no debería renunciar a este análisis. ".Su anexión a una teoría general del materialismo histórico", sin un replanteo de su objeto, no puede más que reproducir sus estigmas, por más que se hable de una teoría crítica de la sociedad como ha pretendido serlo siempre el marxismo" (Trinchero, 1992:101)

Por último y en relación al tema que nos ocupa, lo que se cuestiona, no solo a Terray sino a todo el marxismo estructuralista, es el carácter ahistórico de sus análisis (que lo liga a los desarrollos antropológicos anteriores). Ortner (1984); Llobera (1980). Debido a la fuerte presencia de supuestos estructuralistas, las

\footnotetext{
${ }^{9}$ Recordemos las críticas de susstantivistas como Sahlins, Dalton, Polanyi y las acusaciones de "etnocentrismo" que suscitaba la aplicación de estas categorías económicas a sociedades no capitalistas.
} 
tipologías socioeconómicas, modos de producción y otros factores se nos presentan como objeto de un análisis específico de formaciones sociales concretas e históricas, pero estas son abordadas como si carecieran de historia. "Al estudiar la articulación interna de estas sociedades se han negado a considerar las condiciones que presidieron su aparición y disolución" (Llobera, 1980:211)

Frente a los marxistas estructuralistas, la Escuela de la Economía Política, a la que nos referiremos a continuación, recuperará la perspectiva histórica y trabajará en la creación de una antropología Histórica.

Inspirada en teorías de la sociología política como la del sistema mundial de Wallerstein y la del Subdesarrollo de Gunder Frank, y también en contraste con el marxismo estructural que había centrado preferentemente su atención en las sociedades como unidades cerradas, la escuela de la Economía Política se ocupar de los sistemas político económico regionales de gran escala. Dado que intentaron combinar este enfoque con el trabajo de campo tradicional en comunidades específicas o microregiones, sus investigaciones tomaron la forma de estudios sobre los efectos de la penetración capitalista sobre estas.

El énfasis puesto en los procesos regionales de amplio alcance remite a la perspectiva del sociólogo Imanuel Wallerstein (1991) quien define su enfoque de los sistemas mundiales como una ciencia que diluye las diferencias entre antropología, economía, sociología y ciencia política, constituyendo una sola.

Se trata de una ciencia social histórica, que se propone superar tanto el "ahistoricismo universalizante", como las "generalizaciones transhistóricas" y las "narraciones particularistas". Dirá Wallerstein al respecto que no hay historiadores ni científicos sociales," [...] sino científicos sociales históricos que analizan las leyes generales de sistemas particulares y las secuencias particulares mediante las que se han desarrollado estos sistemas (deliberadamente, no empleamos el tiempo gramatical que se conoce como 'presente etnográfico)" (Wallerstein, 1991: 405).

El análisis de los sistemas mundiales pone en cuestión la unidad de análisis tradicional, sustituyendo el término sociedad por el de "sistema histórico"; término que subraya la unidad de la ciencia histórica. Toma como límites definitorios de un sistema histórico "aquellos en los que el sistema y la gente que se encuentran dentro de él se reproducen regularmente mediante algún tipo de división estable del trabajo" (Wallerstein, 1991:408). Históricamente se han dado tres de estos tipos, 
siendo la economía mundial capitalista el último de estos sistemas históricos concreto.

Frente al "particularismo" y el "universalismo", Wallerstein propone que la perspectiva del sistema mundial es un marco de referencia que abarca el tiempo y el espacio suficiente para observar las lógicas y dinámicas básicas de los procesos sociales. Estas lógicas no deben ser consideradas eternas pues la naturaleza de la organización social cambia a largo plazo.

Esta ciencia social histórica es el marco científico donde pueden establecerse comparaciones y donde adquieren sentido los estudios históricos. Estudios que, en realidad, son medios para la acción política, ya que la propone como una ciencia "que pueda moverse en la incertidumbre de la transición, que contribuya a la transformación del mundo clarificando las alternativas sin apelar al apoyo de una creencia en el triunfo inevitable del bien". En este sentido Wallerstein se presenta como un marxista crítico y fuertemente historicista que toma distancia del "marxismo frecuentemente distorsionado hasta aparecer como una teoría mecanicista [...] una teorización idealista y abstracta." (Llobera: 230)

La tesis de que el mundo constituye una totalidad de procesos múltiples interconectados y que los intentos por analizarlos separadamente son estériles fue planteada en el mismo campo de la antropología por Eric Wolf. Su libro " Europa y la gente sin historia" aparecido en 1982 constituyó un hito y se presenta hoy como una referencia ineludible dentro de la Escuela de Economía Política.

Wolf (1990) toma distancia de la construcción tradicional del objeto antropológico: el estudio de las sociedades primitivas "la gente sin historia" como microcosmos supuestamente aisladas del mundo exterior (un mundo de bolas de billar socioculturales que se desplazan en una mesa de billar universal) y de perspectivas que han soslayado el análisis de las transformaciones por las que han atravesado estas sociedades como consecuencia de la expansión capitalista.

Propone recuperar para las ciencias sociales la economía política y recurrir al materialismo histórico para analizar las transformaciones particulares que produce la dinámica de acumulación capitalista; los procesos que afectan y cambian las vidas de las poblaciones locales. A partir de esta teoría, marca los elementos significativos que operan en estos procesos y sus combinaciones sistémicas en el tiempo histórico. Al mismo tiempo tiene la precisión suficiente para explicar las diferencias 
significativas que distinguen a cada una de estas combinaciones de todas las demás; en este caso al capitalismo de todas las demás combinaciones históricamente conocidas (Wolf, 1990: 37).

Se trata de una historia informada teóricamente y de la teoría informada históricamente " [...] que deben conjuntarse para explicar poblaciones especificables en el tiempo y en el espacio, tanto como resultado de procesos significativos, cuanto como portadores de ellos" (Wolf, 1990: 37).

Reconoce como contribuciones a la historia informada teóricamente: A Gunder Frank (teorías del subdesarrollo) y Wallerstein (teoría del Sistema Mundial). Sin embargo su foco de atención (como el centro subyugó a la periferia) no permitió tener en cuenta la gama y variedad de esas poblaciones, de sus modos de existencia antes de la expansión europea y el advenimiento del capitalismo y la manera en que estos modos fueron penetrados, subordinados, destruidos o absorbidos por el capitalismo.

Esto es precisamente lo que se propuso hacer en "Europa y la gente sin historia", dar el paso hacia la teoría informada históricamente ("historia en el sentido de exposición analítica del desarrollo de las relaciones materiales que se mueven simultáneamente en el nivel del sistema general circundante y en el micro nivel" (Wolf, 1990: 39).

Esta insistencia de la importancia de la historia para los estudios antropológicos no es novedosa, pero si lo es su compromiso por construir una antropología totalmente histórica y su trabajo sistemático en torno a este propósito. Sin embargo su visión de la historia esta afectada, según Ortner (1984), por los problemas derivados de que el mundo está centrado en el capitalismo. Esta suposición de que todas las sociedades que estudiamos han sido penetradas por el sistema capitalista y que, en consecuencia, todo lo que observamos en nuestro trabajo de campo debe comprenderse como habiendo sido conformado en respuesta al mismo, impide reconocer "la verdadera cultura", la estructura y organización, y en definitiva la propia historia de esos pueblos. "La historia es tratada a menudo como algo que llega, como un barco, desde fuera de la sociedad en cuestión. Así no vemos la historia de una sociedad, sino el impacto de nuestra historia sobre esta sociedad [...] Con este enfoque nunca podremos saber como era el otro sistema en sus aspectos únicos y "tradicionales" (Ortner, 1984:143). 
Este cuestionamiento, dice Ortner, acerca de si realmente podemos conocer al "otro", está presente en un número de trabajos recientes. Frente a eso responde que es posible, que hay que tratar y que es justamente el aporte distintivo de la antropología a las ciencias humanas, la ubicación "en el terreno" y el producir conocimientos a partir del trabajo de campo, lo que coloca a los antropólogos en posición de ver a la gente no simplemente como reactores pasivos sino como agentes activos y sujetos de su propia historia.

Hasta aquí hemos realizado un muy rápido recorrido por la teoría antropológica contemporánea intentando indagar acerca de cómo se presenta la dimensión histórica en sus desarrollos. La necesidad de reducir este trabajo a unas pocas páginas nos ha obligado a detenernos sólo en algunas de las teorías y obviar otras. No hemos mencionamos por ejemplo a M. Sahlins quien en su trabajo "Islas de historia" anuncia que, aunque polemizando con los planteos de Wolf, él también ha "descubierto la historia". Tampoco hemos considerado a la antropología geertziana, aunque haremos referencia indirectamente a ella cuando nos ocupemos brevemente de la "historia de inspiración etnográfica" a la que haremos referencia en el punto siguiente.

\section{La historiografía contemporánea y los encuentros con la antropología}

Así como la dimensión histórica se incorpora con fuerza en la teoría antropológica de las últimas décadas, el trabajo de los historiadores fue impactado por los desarrollos de la antropología contemporánea.

Esta influencia de la antropología se reflejó quizás con mayor nitidez y más tempranamente en la historiografía francesa e inglesa al admitir estas que, además de la dimensión material económica explicando la diversidad social y cultural, se interponían los sistemas de representación colectivas y que en este análisis debían incorporarse a sujetos hasta ese momento olvidado por la historia oficial, las clases subalternas.

La Escuela de los Anales constituye una referencia reconocida al poner las cuestiones materiales, las formas culturales y sus modos de significación en una perspectiva de estructura compleja y en la "larga duración". 
Sin embargo, según Auge (1995) el concepto de larga duración de Braudel procede de un "voluntarismo intelectual" que puede atribuirse a la influencia de las reglas del método sociológico de Durkheim que invitaba a alejarse del individuo y del suceso particular para hacer detenerse en lo reiterado, en las regularidades de las cuales pudieran inducirse leyes. "Es por esto que hasta 1970 las grandes indagaciones que recurren a la medición y se refieren a serie de datos abstractos sobre la realidad, eran todo lo contrario de la antropología más holística y monográfica que se estaba desarrollando mientras tanto. (Auge, 1995: 22)

Es durante los 70 cuando se produce un mayor acercamiento en la construcción del objeto al modelo antropológico de algunos historiadores. Los métodos cuantitativos no habían hecho posible la recuperación de la experiencia de los nuevos sujetos históricos y la mirada se vuelca a la antropología.

Auge (1995:23) menciona como ejemplos de este nuevo desarrollo historiográfico a Le Goff, Nathan Watchel, C. Guinzburg y G. Levi.

- Le Goff llevó adelante su seminario de antropología histórica, expresión con la que designa un esfuerzo por llegar, lo mismo que el etnólogo, al nivel más inmóvil, más estable de las sociedades. Sugería reanudar los lazos entre historia y etnología adoptando una perspectiva comparada muy amplia basada en el rechazo explícito de un punto de vista etnocéntrico.

- Nathan Watchel: quien combina, en su trabajo sobre los chipaya de Bolivia, etnografía y trabajos en archivo; procedimiento complementario de dos modos de enfoque distinto (el histórico y el antropológico) puestos al servicio de un mismo objeto: la aprehensión de una sociedad en su devenir y en su presente. (Auge, 1995: 24)

- C. Guinzburg y G. Levi y el movimiento de la "microhistoria". Esta perspectiva propone el estudio de fenómenos socio antropológicos en su vertiente histórica a muy pequeña escala de observación del sistema [una aldea, una familia, un individuo] para poder analizar ciertos procesos más generales y tipificarlos.

Frente a la historia etnográfica serial de los Annales que según Furet implicaba que la historia de las clases subalternas en las sociedades industriales sólo podía ser analizada desde una perspectiva estadística, Guinzburg desarrolla una "forma peculiar de historia narrativa de tipo antropológica" donde articula "la 
dimensión microscópica" con la dimensión contextual a través del estudio intensivo de material documental. El episodio, la historia de caso, se proyectaba en un contexto histórico cultural y en ese sentido su relevancia es doble: como ejemplificación de un particular problema historiográfico, por ejemplo la relación entre cultura alta y baja, y en cuanto a la ilustración de la cultura de un específico grupo social. ${ }^{10}$

Entre quienes Auge no menciona, pero que sin duda no pueden ser obviados al referirnos a la historia que recibe el "estímulo antropológico", se encuentran los historiadores marxistas británicos E. Hobsbawn y E. P. Thompson y los enrolados en la "historia etnográfica" o "antropológica, cuyo principal exponente quizás sea R. Darton.

\section{La historia social de E. P. Thompson}

Dentro de la extensa obra de Thompson destacamos fundamentalmente "La formación de la clase obrera en Inglaterra" y "Miseria de la Teoría". En este último trabajo, como señalábamos más arriba, Thompson polemiza con las posiciones de Althusser acerca de la historia a la que califica de "teoricista" ya que desconoce completamente la elaboración de la historiografía como trabajo empírico, sin el cual no puede teorizarse.

Thompson propone un marxismo cultural, que se ocupa sobre todo de las formas de representación y manifestación de los contenidos de clase. El análisis de clase, dirá, no puede reducirse ni derivarse directamente de la estructura. No hay creación de una clase sino en la lucha de clases y en el proceso en el que se crean formas culturales específicas.

Y en el intento de dar cuenta de la formación de clase como proceso activo de creación, reconoce la influencia y el "estímulo antropológico". Este " [...] no surte su efecto en la construcción de modelos, sino en la localización de nuevos problemas, en la percepción de problemas antiguos con ojos nuevos, en el énfasis sobre normas o sistemas de valores y rituales, en la atención a las funciones expresivas de

\footnotetext{
${ }^{10}$ Esta articulación de "la dimensión microscópica" con la dimensión contextual puede verse por ejemplo en "El queso y los gusanos", donde Guinzburg reconstruye el mundo del molinero friulano Menocchio a trav,s de la documentación producida por los inquisidores que lo mandaron a la hoguera (Guinzburg, 1994).
} 
las diversas formas de motín y revuelta y en las expresiones simbólicas de la autoridad, el control y la hegemonía" (Thompson, 1992:64)

Sin embargo este diálogo con la antropología no lo es con toda la antropología social, ya que la historia social no puede asociarse con disciplinas "antihistóricas" como la representada por Radcliffe-Brown o Levi- Strauss, sino con la "antropología marxista". Tampoco lo es con aquella antropología marxista que en un enfoque reduccionista acepta la analogía de la base y la superestructura y da prioridad interpretativa a lo económico en un sentido restringido. La confluencia que propone como la más fecunda es, en cambio, con una antropología que ayude a dar cuenta de como "[...] el cambio histórico sucede, no por que una "base" determinada deba dar lugar a la "superestructura" correspondiente, sino por que los cambios en las relaciones de producción se experimentan en la vida social y cultural, se refractan en las ideas de los hombres y en sus valores, y son cuestionados en sus acciones y creencias" (Thompson, 1992: 83).

\section{La "historia con espíritu etnográfico" de R. Darnton}

Dentro de las distintas tendencia agrupadas en la "historia cultural"11, nos interesa especialmente destacar aquella que se reconoce como "historia Antropológica" y hacer una mención a un trabajo de R. Darton, publicada en 1984, que se ha convertido en una referencia ineludible de este nuevo enfoque historiográfico.

Se trata de una serie de ensayos "La gran matanza de gatos y otros episodios en la historia de la cultura francesa", libro que provocó gran interés en el público en general y entre los historiadores en particular, y que ha dado lugar a importantes debates en varios números de "The Journal of modern History".

Darnton (1987) caracteriza a esta historia como un empeño que pretende el estudio de las creencias populares colectivas como objeto etnográfico; cosa que reconoce explícitamente haber tomado de Geertz cuando explica los hechos sociales como "textos". Los poderes de desciframiento de significados de la antropología geertziana

\footnotetext{
${ }^{11}$ La historia cultural, que en gran medida hereda la trayectoria de los Anales aunque desarrolla un camino propio, podría ser definida como la $\mathrm{H}$. que se ocupa de las representaciones sociales producidas por los objetos y pr cticas recorridos sustantivamente por la escritura impresa (Barrancos, 1996: 333).
} 
le otorgan al historiador, dirá Darnton, poderes adicionales de interpretación sobre su material de archivo.

Se trata de llegar a los hechos del pasado como lo hace el antropólogo: "poniéndose en contacto con la otredad", "descifrando textos opacos", "desechando el falso sentimiento de familiaridad" y buscando "la dimensión social de su significado". Pues estos hechos, no tienen simplemente lugar sino que suceden cargados de sentidos. (Darnton, 1987:12-14)

La cuestión es tratar de combinar el registro de lo que está sucediendo (historia episódica) con el de cómo la gente los entiende y se los representa (una historia de las mentalidades). Para ello hay que desenhebrar temporalmente el acontecimiento y engarzarlo en un sistema histórico de significados y esto lo hace "pasando del texto al contexto y regresando de nuevo a este hasta lograr encontrar una ruta en un mundo mental extraño" (Darnton, 1987:13)

Comprender una cultura implica entonces "reencontrar las significaciones conferidas en las formas simbólicas que ella trata" y para realizar esto hay un método: ir del texto al contexto y viceversa, es decir relacionar cada empleo individualizado y localizado de tal o cual símbolo con el "universo de significaciones" que le da sentido (y en esto la referencia es Geertz).

De este modo la antropología le ofrece un camino, un proyecto, un concepto. (Chartier, 1995: 82). Un camino: ingresar a una cultura (diferente) a partir de la "opacidad" incomprensible de un rito, de un texto, de un gesto. Un proyecto: intentar ver las cosas desde el punto de vista del nativo. Un concepto: el que define la cultura como un universo simbólico, en la que los símbolos compartidos sirven para pensar y actuar, clasificar y juzgar.

\section{Consideraciones finales}

Luego del esquema histórico universal del evolucionismo y pese a voces discordantes como la de Evans-Pritchard e intentos fallidos como los de Boas de "construir un enfoque histórico de la cultura", durante la primera mitad del siglo XX, la dimensión diacrónica permanece fuera del alcance de los antropólogos. La historia queda anulada ante la primacía de lo presente y lo estático. 
La perspectiva sincrónica es convergente con los intereses del funcionalismo y el estructural-funcionalismo y la función "práctica" asignada por el colonialismo a la disciplina. No es que negaran la existencia de procesos históricos ni que fueran "ingenuos ignorantes" del cambio y el conflicto, sino que no estaban preparados teóricamente más que para describir como funciona la sociedad "nativa", para ver el mantenimiento y la continuidad estructural; conocimientos "prácticos" que les servirían para poder administrar eficientemente estas sociedades.

Tras la segunda Guerra Mundial y con la crisis de la dominación colonial se desarrollan nuevas construcciones de la teoría antropológica en las que se redescubre la historia. El dinamismo británico y el francés reconocen que las sociedades tribales encerraban cambios y contradicciones, que tenían una historia y que los movimientos sociales que se estaban sucediendo reflejaban no sólo las transformaciones provocadas por la situación colonial sino la estructura del pasado local.

La convergencia entre historia y antropología parecía para entonces una realidad, pero en el estructuralismo lévistrossiano y aún el marxismo estructuralista la perspectiva histórica se diluye. En el primero porque si el tiempo histórico no es sino la posibilidad de que se manifiesten las invariantes estructurales, la historicidad pasa a ser secundaria. En el segundo, porque pese a reivindicarse marxistas, han evitado, como lo manifiestan Llobera (1980) y Ortner (1984), una de las cuestiones más centrales en Marx: el presente como historia y han abordado las sociedades en estudio como si carecieran de ella. Recién con la Escuela de la Economía Política nos encontramos con un grupo comprometido con una antropología totalmente histórica, aunque, como también señala Ortner, ellos tampoco logran ver la historia de la sociedad en estudio, sino en todo caso el impacto de "nuestra historia" (la del desarrollo del capitalismo) sobre las mismas.

Frente a este modelo "demasiado economicista, demasiado estrictamente materialista" de la economía política, que no habla lo suficiente de relaciones de manipulación, control, y por lo tanto no es "suficientemente política" (Ortner, 1984:142), la historiografía inglesa nos ofrece en los trabajos de E. P. Thompson una propuesta que, también desde el marxismo, recurre a los desarrollos antropológicos y a la cultura para analizar la formación y relaciones de clase y la cuestión del poder. Desde este enfoque se desecha una "definición restringida de lo 
económico", se plantea a la clase como formación "económica" y también "cultural" y se señala que la determinación "de última instancia" puede abrirse paso a través de las formas culturales o las económicas.

Este "giro culturalista" de Thompson, quien evoluciona hacia un marxismo que se ocupa sobre todo de las formas de representación y manifestación de los contenidos de clase, ha implicado no sólo una renovación conceptual sino también temática. La "historia desde abajo" que él y otros británicos como Hobsbawn proponen y el replanteo de la práctica tradicional del historiador y de las fuentes y métodos usados, también están presentes en la historiografía italiana a través de la microhistoria: una historia narrativa de tipo antropológica. El análisis propuesto por la microhistoria está conectado, precisamente, con una percepción de alteridad de la experiencia pasada; del pasado como "país exótico".

Paralelamente, desde otra corriente historiográfica, la llamada "historia cultural", lo que atrae a Darnton a la etnografía y lo que "legitima" el empleo de ese enfoque es, en primer lugar que esta tiene experiencia en descifrar "textos opacos" y en "entrar en mentalidades extranjeras"; y en segundo lugar, que procura ver la vida social desde el "punto de vista del nativo".

Estos desarrollos dan cuenta de la significativa influencia que la antropología cultural, como antropología simbólica e interpretativa, ha ejercido en parte de la historiografía contemporánea. Al mismo tiempo que en la antropología de las últimas décadas se observa un cambio teorico como un movimiento que yendo de la estructura y sistemas a las personas y las practicas implica también el desplazamiento de un análisis sincrónico, estático a uno procesual y diacrónico.

Estas convergencias tienen que ver con el hecho de que las ciencias sociales se están haciendo menos especializadas y diferenciadas en sus abordajes y metodologías, más interdependientes en el análisis para poder comprender un mundo que se complejiza. Pero además la antropología e historia, guardan una relación de proximidad que corresponde a la naturaleza misma de su objeto: " [...] si el espacio es la materia prima de la antropología, se trata de un espacio histórico, y si el tiempo es la materia prima de la historia, se trata de un tiempo localizado y, en este sentido un tiempo antropológico" (Auge, 1994:15).

Como señala Cohn (Neufeld, 1994) "comparten la otredad como objeto" y esto implica un esfuerzo especial por pensar al otro, por trasladarse a un sistema 
social y cultural en el que el sentido de las palabras y de las cosas se nos escapan continuamente, por atender a la multiplicidad de las condiciones objetivas y de las representaciones sociales, contradictorias, ambiguas, a partir de los cuales los hombres construyen el mundo y sus acciones.

\section{Referencias bibliográficas}

Althusser Louis, y Balibar, Etienne (1978). Para leer el capital. México: Siglo XXI, Augé, Marc (1994). Hacia una antropología de los mundos contemporáneos. Barcelona: Gedisa. Arostegui, Julio (1995). La investigación histórica: Teoría y método. Barcelona: Crítica. Balandier, George (1963). Sociologie Actuelle de 'I Afrique Noire. Paris: PUF.

Barrancos, Dora (1996). Problemas de la "historia Cultural. Triangulación y Métodos, Dialógica,1(1), 327-342.

Chartier, Roger (1995). Texto, símbolos y frenchness. En Luz y contraluz de una historia Antropológica. Eduardo Hourcade, Cristina Godoy y Horacio Botalla,Eds. Buenos Aires: Biblos.

Darnton, Robert. (1987). La gran matanza de gatos y otros episodios en la historia de la cultura francesa. México: FCE.

Evans-Pritchard, Edward (1974). Ensayos de antropología Social. Madrid: Siglo XXI.

Gaboriau, Marc (1969). Antropología estructural e historia. En Estructuralismo e historia. José Sazbon, Comp. Buenos Aires: Nueva Visión.

García-Canclini, Néstor (1982). Las culturas populares en el capitalismo. México: Nueva Imagen.

Gluckman , Max (1963). Order and rebellion in Tribal Africa. New York: Free Press

Godelier, Maurice (1967). Sistema, estructura y contradicción en El Capital. En Problemas del estructuralismo. Algirdas Greimas, Ed. México: Siglo XXI.

Guinzburg, Carlo (1994). El queso y los gusanos. Barcelona: Atajos.

Guinzburg, Carlo (1995). Microhistoria: dos o tres cosas que sé de ella. Entrepasados, V(8), 51-73

Harris, Marvin (1985). El desarrollo de la teoría antropológica. Barcelona: Siglo XXI.

Hindes, Barry y Hirst, Paul (1979). Los modos de producción precapitalista. Barcelona: Península,. Hourcade, Eduardo, Godoy, Cristina y Botalla, Horacio, Comp. (1995). Luz y contraluz de una historia Antropológica. Buenos Aires: Biblos.

Lefebvre, Henry (1969). Reflexiones sobre el estructuralismo y la historia. En Estructuralismo e historia. José Sazbon, Comp. Buenos Aires: Nueva Visión.

Lévi-Strauss, Claude (1984). Antropología estructural. Buenos Aires: EUDEBA.

Lévi-Strauss, Claude (1975). El pensamiento salvaje. México: FCE.

Llobera, José (1980). Hacia una historia de las ciencias sociales. Barcelona: Anagrama.

Neufeld, María Rosa (Manuscrito no publicado). Acerca de antropología Social e historia: Una mirada desde la antropología de la educación. 
Ortner, Sherry (1984). Theory in Anthropology since the Sixties. Comparative Studies in Society and History 26: 126-166.

Radcliffe Brown, Alfred (1975). El método en la Antropología Social. Barcelona: Anagrama.

Sazbon, José (1969). historia y Sistemas en Claude Lévi-Strauss. Estructuralismo e historia. José Sazbon, Comp. Buenos. Aires: Nueva Visión.

Sazbon, José, Comp. (1969). Estructuralismo y antropología. Buenos Aires: Nueva Visión

Terraym, Emmanuel (1971). El marxismo ante las sociedades primitivas. Buenos Aires: Losada

Thompson, Edward (1992). Folklore, antropología e historia Social. Entrepasados, II(2),63-86

Trinchero, Hugo (1992). Antropología Económica. Buenos Aires: CEAL.

Tullio-Altan, Carlo (1969) Estructuralismo y funcionalismo en Lévi-Strauss. En Estructuralismo y antropología. José Sazbon, Comp. Buenos Aires: Nueva Visión.

Wallerstin, Immanuel (1991). Análisis de los Sistemas Mundiales. En La teoría Social hoy. Anthony Giddens y Jonathan Turner, Eds. México: Alianza

Wolf, Eric (1984). Europa y la gente sin historia. México: FCE. 